\title{
Memórias de UM CORPo ESQUeCido
}

Jorge Goia ${ }^{\star}$

\begin{abstract}
RESUMO
Este artigo procura investigar os variados papéis ocupados pelo corpo humano enquanto objeto de estudo da psicologia. Utilizando recortes da história das ciências bio-médicas e da psicologia no Brasil, o autor propõe três periodos para sua análise: uma fase de determinismo biológico; depois, o abandono do corpo durante a hegemonia da psicanálise; e por fim a proliferação das terapias corporais impondo padrões de saúde. Apesar de apontarem pesos diferentes para o dualismo corpo/mente, estes modelos de psicologia continuam ativos. Uma nova abordagem para o corpo e a psicologia precisaria então discutir os aspectos políticos dentro do projeto das ciências modernas.
\end{abstract}

Palavras-chaves: Corpo. Psicologia. História.

\section{MEMORIES OF A FORGOTTEN BODY}

\begin{abstract}
This article aims to research the multiple roles of the human body within studies of psychology. The author uses various moments of bio-medical sciences and psychological history in Brazil to propose three periods to analyse: a time of biological determinism; after that, a desertion of the body during the hegemony of psychoanalysis; and finally the proliferation of body therapies imposing patterns of health. Even though they give different emphases to body/mind dualism, these psychological models remain active within the modern science project. A new approach to the body and psychology would need therefore discussing political aspects of modern science project.
\end{abstract}

Keywords: Body. Psychology. History.

\footnotetext{
* Doutor em Psicologia Social pela Universidade do Estado do Rio de Janeiro (UERJ) e pesquisador visitante do Department of Portuguese and Brazilian Studies, King's College London. 27 Nevil House, Brixton, London - SW9 7TW.

E-mail: jorge.goia@somaterapia.com.br
} 


\section{MEMÓRIAS DE UM CORPO ESQUECIDO}

Corpo e psicologia contam suas trajetórias com capítulos que se cruzam e se afastam no decorrer do percurso dos últimos séculos da história da humanidade ocidental, tempo marcado por grandes transformações sociais, políticas e revoluções científicas/tecnológicas. Não são muito distantes os períodos em que as ciências que estudam o corpo, a biologia e a medicina especialmente, se digladiaram com a psicologia pelo território da compreensão do comportamento humano, ganhando hegemonias fátuas. Disputa recorrente, que assume outros tons com a vertiginosa rapidez imprimida nestes últimos anos, indicando a necessidade de um olhar atento sobre um passado que ainda é presente.

Se o que sempre moveu as ciências foram descobertas que geraram informações para controlar e dominar as ameaças à vida humana, aconteceram também movimentos com efeitos não programados e que trouxeram conseqüências tão ameaçadoras quanto as anteriores. Para o sociólogo alemão Ülrich Beck (2001), a modernização criou uma sociedade dos riscos, ${ }^{1}$ na qual a imprevisibilidade das técnicas criadas estabelece uma impossibilidade de controle sobre o futuro.

É nesta sociedade dos riscos que a genética e a cibernética hão de pintar as mais sombrias previsões para além das imaginadas na literatura e no cinema. Não há dúvidas de que estamos diante de um tempo de mudança, talvez proporcional em dimensão ao germinado pelas Luzes diante do obscurantismo religioso. $\mathrm{O}$ fogo roubado por Prometeu, o conhecimento dos deuses, cada vez mais agora arde em brasas nas nossas mãos e, ou o jogamos fora, ou fazemos dele a esperança de continuar perguntando: para onde estamos indo?

O corpo humano é cartografado pelo Projeto Genoma enquanto minúcias, microscópicas e deterministas, que possam ser manipuladas. Por seu lado, a cibernética busca cada vez mais uma inteligência artificial que copie e reproduza a experiência humana. Passado e futuro ganham inéditas articulações: a previsibilidade gerada pelos DNAs indicando substituições dos mecanismos "falhos" por um automatismo seguro; o virtual invadindo e modificando o real, numa mistura de sensações atemporais; julgamento prévio intervindo no presente antecipado; uma racionalidade objetiva que prescinda de emoções e sentimentos. Talvez, resumindo estas possibilidades, as ciências cheguem à derradeira descoberta do humano sem corpo, descolado do tempo, isento e soberano sobre a vida e a morte.

Esta pretensão, por mais estapafúrdia ou utópica que soe, tem suas raízes numa crença ancestral que permeou as grandes questões filosóficas: a existência de duas instâncias de realidade, uma interna a todo ser humano e outra externa ao mundo que sempre esteve lá. Dentro e fora. O corpo e suas funções biológicas, intermediário destas duas instâncias "fundamentais", torna-se apenas veículo de percepção/expressão entre uma humanidade internalizada na mente e uma outra onipresente no ambiente. ${ }^{2}$

É neste quadro dualista, no qual o corpo humano alternou posições hierárquicas de importância e de objeto de estudo, que pretendo construir um olhar sobre a história da psicologia no Brasil. Os recortes escolhidos tiveram duas ra- 
zões: o movimento em busca de um reconhecimento como ciência por parte da psicologia e a relação de proximidade/afastamento com outras ciências que estudam o corpo humano. Assim, três períodos marcam estas memórias do corpo com a psicologia. Primeiro, uma fase determinista, na infância da ciência brasileira; depois externalizado pelo behaviorismo e quase ignorado pela hegemonia da psicanálise; e por último, reencontrado numa nova mitificação de um corpo ideal, na proliferação das terapias corporais.

\section{CORPO COMO JULGAMENTO DE VERDADE}

O corpo nu foi um dos primeiros choques culturais na constituição do colonialismo europeu no Novo Mundo. Já o escrivão português Pero Vaz de Caminha registrou suas impressões iniciais sobressaltado com a inexistência do sentimento de vergonha entre os nativos que cá encontrou. Os cobertos sob panos, catequizados na civilização ocidental, não conseguiam compreender quem eram aqueles estranhos seres, humanos? , com seus rituais selvagens e costumes mais próximos dos animais. E nem podiam compreender, confinados que estavam nas suas vestes cristãs.

Se o conceito de alma era o que definia a idéia de "psique", psicológico ou interioridade, não estava com ele também o temor pelo corpo desnudo em sua animalidade externa? Talvez Espinoza, o filósofo que ousou afrontar a crença na natureza divina da humanidade dualista, não tivesse a dimensão do estrago que a "excomunhão" de suas idéias causou no nascimento da ciência moderna: as primeiras contestações contra a impossibilidade de se estudar a "psique" ainda se calcavam na mesma divisão cristã de externo e interno, carne e alma, agora corpo e mente.

Nos séculos dominados pelo obscurantismo religioso, a justificação para a importância de se cuidar da alma foi os dogmas cristãos. Na ciência que aqui chegou com D. João VI, em 1808, os argumentos para se estudar o corpo eram os dogmas positivistas. Lilia Schwarcz, em "O espetáculo das raças" (SCHWARCZ, 1995), ao mapear os anos que marcaram o surgimento de uma vida acadêmica no Brasil, faz uma história das idéias científicas sobre o conceito de raça e mostra como, no Brasil da miscigenação, este debate encobriu a rigidez social estabelecida pelos critérios diferenciados de cidadania.

Ao pesquisar personagens pioneiros da sciencia brasileira, Schwarcz mostra como eles escaparam do paradoxo entre a aceitação da existência de diferenças humanas inatas e o elogio do cruzamento para a constituição de uma sociedade em vias de estabelecimento como projeto nacional (finais do século XIX). Estes homens, segundo a autora, quase "sacerdotes positivistas", aceitaram o desafio de importar teorias estrangeiras - que condenavam o cruzamento racial - e as adaptaram a um povo já marcado por esta mistura.

A década de 1870 é o período emblemático do processo de emergência de uma nova elite que adota os princípios liberais associados ao discurso científico evolucionista e determinista para analisar as tensões internas da sociedade da época (fim da Guerra do Paraguai, Lei do Ventre Livre, chegada de imigrantes europeus, 
iminente término da escravidão). Nas palavras de Silvio Romero, citado por Schwarcz, as "classes perigosas" transformaram-se em "objetos de sciencia", pois era a partir da ciência que se reconheciam diferenças e se determinavam inferioridades.

Esta nova elite intelectual fez da ciência uma espécie de sacerdócio, com todas as implicações permitidas pela metáfora: fé, crença, disputa pelo acesso à Verdade. Se na Europa alguns pilares positivistas estabelecidos já estavam abalados, no Brasil se consumiam modelos evolucionistas e social-darwinistas, justificando teoricamente práticas imperialistas de dominação interna (a inferioridade racial) e externa (o colonialismo). Esta importação de uma ciência que desabona as possibilidades do país mestiço com uma elite européia teve seu caráter histórico vinculado à necessidade de um instrumento conservador na construção de uma identidade nacional.

As doutrinas raciais do século XIX, nascidas na Europa e nos Estados Unidos, não tinham uma unicidade, apesar de utilizarem a mesma noção de evolução social. O discurso racial apareceu como uma reação ao Iluminismo e seus ideais humanistas, trazendo uma variante aos pressupostos burgueses de cidadania. Foi este modelo determinista que se estabeleceu por aqui. "Naturalizar as diferenças significou, nesse momento, o estabelecimento de correlações rígidas entre características físicas e atributos morais. [...] Da biologia surgiam os grandes modelos e a partir das leis da natureza é que se classificavam as diversidades" (SCHWARCZ, 1995, p. 65).

A função política que este modelo representou pode melhor ser entendido no embate entre medicina mental e direito penal $^{3}$ que se desenvolveu no século XIX. A antropologia criminal defendeu o argumento de que a criminalidade era um fenômeno físico e hereditário. A eugenia passou a ser um terreno fértil no qual surgiram interpretações biológicas para os comportamentos humanos. Era o nascimento da craniologia técnica, da frenologia e da antropometria, teorias que vinculavam a capacidade humana pelo tamanho e proporção do cérebro.

Um dos casos de maior repercussão desta "ciência racista" foi o de Febrônio Índio do Brasil, que na segunda década do século XX aterrorizou o Rio de Janeiro com crimes aparentemente sem motivos, foi preso e tornou-se um "objeto de estudo" de Heitor Carrilho, médico psiquiatra que se tornou figura marcante no surgimento desta ciência com poder de revelação e de verdade. $\mathrm{O}$ antropólogo Peter Fry (1985), ao estudar o caso, vai construir uma articulação entre o saber e o poder (ou entre a medicina e o direito) mostrando a instituição da psiquiatria como polícia científica. Fry mergulhou nos laudos de Carrilho sobre Febrônio para investigar a "lógica" que movimentou este período da ciência brasileira.

\footnotetext{
A morfologia do corpo de Febrônio é escrutinada e sujeita às múltiplas medidas da antropometria. [...] Mesmo que seja possível argumentar que há um certo grau de 'objetividade' nestes dados, e que eles são efetivamente descrições do que é visível do corpo de Febrônio, Carrilho não deixa também de atribuir, construir uma relação entre o visível e o invisível, entre a aparência do corpo, suas práticas sexuais e suas glândulas internas. (FRY, 1985, p. 135)
} 
Assim, tutelada pelas teses eugênicas, iniciava-se no Brasil a constituição da psicologia como ciência. Inicialmente vinculada à medicina, através da psiquiatria, os estudos da emergente psicologia também tratavam das questões de Higiene Pública, dos hábitos e comportamentos de uma sociedade com graves ameaças epidêmicas, como a febre amarela. E o pano de fundo deste período estava nos problemas sociais vinculados pela ciência à miscigenação racial no país. O corpo era o campo de estudo e de estabelecimento de verdades deterministas.

\section{CORPO ESCONDIDO}

A psicologia enquanto ciência se apresenta como dispersão do saber e descontinuidade histórica. Acreditando nesta tese, Luiz Alfredo Garcia-Roza (1977) procura justificar a sua existência como conhecimento num espaço marcado por uma não-unidade, que antes de inviabilizá-la, a torna potencialmente rica em diversidade. Pragmático diante do dilema da cientificidade da psicologia, já que sua existência é inexorável, Garcia-Roza procura debater a ascensão do behaviorismo nos primórdios da psicologia científica num período marcado por certo reducionismo biológico.

Como que se rendendo à chantagem do positivismo reinante, a psicologia encontrou na noção de comportamento a realidade empírica que poderia ser observada. Foi o acordo necessário com a biologia sobre os processos que regem o comportamento humano. Para escapar do reducionismo imposto pelas ciências biológicas, e também para não cair nas armadilhas da metafísica, o behaviorismo impôs um outro tipo de matematização, ainda sobre as características físicas observadas, ainda reducionista e determinista.

Fazer ciência é produzir um objeto irredutível. E é exatamente isto que a psicologia não faz quando pretende reduzir os conceitos e princípios psicológicos a conceitos e princípios fisiológicos ou quando julga ser suficiente introduzir um formalismo matemático nas noções empíricas colhidas a partir da observação (GARCIA-ROZA, 1977, p. 22).

Ao fazer do externo, o comportamento passível de observação, seu campo de estudo, o behaviorismo se junta à hegemonia das ciências biológicas e possibilita a tutela da psicologia enquanto saber e conhecimento.

O século XX vai assistir a um boom de pesquisas e práticas psicológicas constituindo o que Garcia-Roza vai chamar de "colcha de retalhos", um espaço marcado por uma diversidade muitas vezes antagônica. No Brasil, depois do início vinculado à medicina e à higiene pública, a psicologia vai se voltar principalmente para a educação, fornecendo bases científicas para a mesma. Com a crescente urbanização e industrialização do país, um novo tipo de cidadão tornava-se necessário. E, tanto escolas como fábricas se valeram dos exames psicotécnicos para preparar e selecionar pessoas capacitadas para um novo tempo e novas funções. A primeira metade do século ficou marcada pela emergência dos laboratórios experimentais de psicologia, nos quais aprendizagem e condicionamento se 
tornaram sinônimos. A psicologia mostrava assim sua utilidade e possibilidade científica para um Brasil que queria ser moderno.

Para Luiz Cláudio Figueiredo (1993), o espaço para a emergência da psicologia surgiu justamente vinculado ao projeto epistemológico da modernidade de busca do conhecimento, da verdade, da plenitude e da integralidade que garantiriam o progresso humano. E para escapar do determinismo biológico, uma outra instância precisou ser valorizada como contra-ponto: "[...] a psicologia não teria surgido como área independente de saberes e cuidados se não se tivesse instituído uma radical cisão corpo-mente em que esta se convertia numa realidade sui generis a atrair atenções especiais" (FIGUEIREDO, 1993, p.19).

Se esta "realidade sui generis" se fixou na observação externa do comportamento nos pressupostos do behaviorismo, a psicanálise tratou de internalizar esta observação: não era mais o externo que interessava como objeto de estudo, mas o inconsciente. As teorias de Freud produziram para a psicologia um distanciamento para com as ciências biomédicas, com o corpo assumindo um mero papel de candelabro que carregaria a luminosidade humana da mente. Mas tanto a observação behaviorista como a escuta psicanalítica desenvolveram-se apoiadas nos aspectos culturais como saída para o conflito entre psicologia e psiquiatria. E foram os educadores e os médicos-psiquiatras que utilizaram ambas como alternativas para uma ciência que cuidasse do ser humano mais como profilaxia do que como intervenção.

A partir da segunda metade do século XX, com a regulamentação da profissão e o surgimento das primeiras faculdades de psicologia, as possibilidades de atuação para a psicologia se ampliam. A clínica passa a ser uma alternativa viável e a psicanálise vira moda nos anos 1970. Jane Russo (1993) constrói um quadro geral da história do movimento psicanalítico no Rio de Janeiro, utilizando as noções de campo (dispersão) e corpo (integração) de Pierre Bourdieu. Para Russo, a história das profissões psi é uma história de transformações de campo em corpo e viceversa, em que o direito de entrada no exercício profissional criou monopólios que foram passando de mão em mão. Nos primórdios, a tutela foi dos médicos-psiquiatras sobre os behavioristas. O surgimento da psicanálise, deslocando para o cultural o que era basicamente biológico, trouxe um novo paradigma e um conflito entre psicólogos psicanalíticos e psicanalistas psiquiatras: as "corporações" psicanalíticas se multiplicam na mesma medida em que os cursos de psicologia proliferam. O "retorno a Freud" do lacanismo, ao mesmo tempo que destitui o monopólio médico e biológico sobre a psicanálise, tenta criar uma nova barreira, o monopólio invisível do hermético, a difusão $p s i$. O rigor é o terreno fértil para as práticas alternativas...

\section{REENCONTRO ASCÉTICO}

A psicanálise, hegemônica na passagem dos anos 1970 e 1980, vai ter seu domínio abalado com a concorrência das chamadas "terapias alternativas". Em meio à salada geral, Wilhelm Reich é o vínculo que produz um novo corpo (no sentido de Bourdieu). Apesar da raiz comum, num primeiro momento o que vai caracterizar as terapias corporais é uma certa indeterminação: o rótulo de 
"bioenergéticos" abriga várias técnicas, neo-reichianas em sua maioria. E, novamente, o que parecia uma nova "terra de ninguém" (difusão desenfreada), vai encontrar seu contrafluxo, desta vez num "retorno a Reich", com a institucionalização da formação reichiana.

Na tese de Russo, Reich e Lacan participam de um encontro inusitado, como figuras evocativas (o retorno a uma ortodoxia) de uma corporação que tenta se fechar em meio à dispersão generalizada do fenômeno $p$ si na cultura brasileira, principalmente em seus extratos médios urbanos. Seriam, portanto, dois lados de uma mesma continuidade da psicanálise, pelo menos como necessidade do sujeito de um trabalho sobre si. A diferença estaria justamente na recuperação do corpo como objeto de estudo.

$\mathrm{O}$ crescimento das terapias corporais introduz um dado novo: a psicologia volta a se encontrar com as ciências biomédicas. E um "corpo ideal" passa a ser procurado. Esta idealização de um corpo saudável se pulverizou em micropolíticas, das "sociedades disciplinares" (FOUCAULT, 1975) às "sociedades de controle" (DELEUZE, 1992), impondo o que Francisco Ortega (2002) chamou de bio-ascese, um processo em que a ideologia do healthism tornou-se hegemônica. Segundo Ortega, a segurança é o que marca esta busca de saúde. A biossociabilidade teria nesta ideologia o seu pressuposto de controle. As técnicas sobre o corpo passam a ser o referencial "ético" que resume a essência de alguém: o cuidado do corpo é o objeto de avaliação do comportamento social.

\begin{abstract}
"As práticas bio-ascéticas fundem corpo e mente na formação da bio-identidade somática, produzindo um eu que é indissociável do trabalho sobre o corpo, o que torna obsoleta antigas dicotomias, tais como corpo-alma, interioridadeexterioridade, mente-cérebro" (ORTEGA, 2002, p. 167).
\end{abstract}

As terapias corporais criaram uma outra referência para o self, dando-lhe uma materialidade biológica, mas a partir de um padrão de funcionalidade que opera ainda como um modo de subjetivação. A integração corpo-mente segue cartilhas de conduta, receitas dietéticas e naturalistas, programas de condicionamento físico, massagens terapêuticas e toda uma gama de procedimentos que buscam um "bem-estar". É no externo ainda que reside a esperança vendida em bulas de saúde.

Assistimos a um novo reducionismo impondo suas regras. E se a psicologia pode ser lida como uma ascese moderna (ORTEGA, 2002, p. 167), urge repensála diante do avanço dos conhecimentos genéticos e das novas tecnologias que parecem querer torná-la obsoleta. Qual a utilidade da psicologia se podemos ir à farmácia da esquina e comprar tranqüilidade em forma de pílulas, ou mudar o que não gostamos no nosso corpo com alguma prótese ou cirurgia plástica? Ou indo além, qual a utilidade da psicologia permanecendo ela no campo das bio-asceses modernas?

A alienação dos indivíduos dos processos sociais e políticos, fazendo-os autoreflexivos em suas individualidades desgarradas do meio em que vivem, produz o que poderíamos chamar de "cosmética da existência". Ao contrário de uma estética 
da existência, esta seria uma "ética" niilista, na qual cada um se preocupa em parecer "saudável", mente e corpo integrados, mas como avestruz, ignorando o sentido político de todos os tipos de produtos que nos são oferecidos para consumo.

O deslocamento das últimas pesquisas de Foucault (1997), do eixo saberpoder para os modos de subjetivação, procurou recuperar as "técnicas de si" dos gregos. Podemos seguir esta seta talhando o "cuidado de si" como construção permanente. A estética como ética da existência e a rebeldia como pragmática de vida produzindo uma "escultura de si" (ONFRAY, 1995), um corpo político: sôfrega taquicardia, insuspeita adrenalina, ou bombas fisiológicas disparadas diante da contemplação, em instantes que uma torrente de substâncias correm levando da placidez ao caos, ou vice-versa. Corpo como o irredutível de cada um, para além do dualismo da metafísica e da ciência moderna. Corpo nos territórios da política do cotidiano, do tesão nosso de cada dia, em que o prazer pode ser bússola nos processos de escolha, a alegria sua sensação e a beleza seu atributo. Corpo e psicologia com um sentido político para escapar do niilismo contemporâneo e das bioasceses modernas.

"O corpo não é assim uma residência provisória de algo superior - uma alma imortal, o universo, ou pensamento - mas o que deixa uma trajetória dinâmica pela qual nós aprendemos a registrar e nos tornamos sensíveis ao que faz o mundo" (LATOUR, 2002). O corpo esquecido pela psicologia se encontra no corpo que aprende a ser afetado (LATOUR, 2002) dos cientistas e pesquisadores do comportamento, dos terapeutas clínicos e pacientes catalogados, dos teóricos do departamento de recursos humanos e dos indivíduos despersonalizados como um dado de pesquisa. A partir desta proposição, uma epistemologia política para o corpo (LATOUR, 2002), a psicologia poderia ser pensada como uma pedagogia de corpos políticos que se afetam e mudam suas relações constantementes, gerando imprevisibilidades e alternativas. Para a psicologia então, o corpo humano não serviria somente para julgamentos de verdade, ou análises reducionistas, nem para receitas de bem-viver, mas produziria a materialidade para enfrentar e fugir dos controles e padrões de uma ciência ainda formatada no dualismo ou no holismo.

\section{Notas}

${ }^{1}$ Segundo Beck vivemos o resultado não do fracasso, mas do próprio sucesso da sociedade industrial. Os riscos agora não estão mais na natureza a ser controlada, mas na própria tecnologia criada pelo homem.

${ }^{2} \mathrm{O}$ antropólogo britânico Tim Ingold mostra que este dualismo é próprio da nossa cultura. Em outras culturas acontece o que ele denomina de embodiment, uma relação de incorporação dos seres vivos com o ambiente.

${ }^{3}$ As duas primeiras faculdades criadas no Brasil foram as de Direito e de Medicina. Era, portanto, nestes campos que o embate intelectual e acadêmico se dava. 


\section{REFERÊNCIAS}

BECK, Ü. La société du risque: sur la voie d'une autre modernité. Paris: Alto: Aubier, 2001.

DELEUZE, G. Conversações. São Paulo: Ed. 34, 1992.

FIGUEIREDO, L. C. Revisitando a Psicologia: da epistemologia à ética das práticas e discursos psicológicos. Petrópolis: Vozes; São Paulo: Educ, 1993.

FOUCAULT, M. Resumo dos cursos do Collège de France. Rio de Janeiro: J. Zahar, 1997.

Vigiar e punir. Petrópolis: Vozes, 1975.

FRY, P. Direito positivo versus direito clássico: a psicologização do crime no Brasil no pensamento de Heitor Carrilho. In: FIGUEIRA, S. Cultura da Psicanálise. São Paulo: Brasiliense, 1985.

GARCIA-ROZA, L. A. Psicologia: um espaço de dispersão do saber. Rádice, Rio de Janeiro, v. 1, n. 4, p. 20-26, 1977.

INGOLD, T. The perception of the environment: essays in livelihood, dwelling and skill. Londres: Routledge, 2000.

LATOUR, B. How to talk about the body?: the normative dimension of science studies. 2002. Disponível em: <http://bod.sagepub.com/cgi/reprint/10/2-3/ 205.pdf>. Acesso em: 10 jun. 2005.

ORTEGA, F. Da ascese à bio-ascese ou do corpo submetido à submissão do corpo. In: RAGO, M.; ORLANDI, L.; VEIGA-NETO, A. (Org.). Imagens de Foucault e Deleuze: ressonâncias nietzschianas. Rio de Janeiro, 2002.

ONFRAY, M. A escultura de si. Rio de Janeiro: Rocco, 1995.

RUSSO, J. O corpo contra a palavra. Rio de Janeiro: Ed. UFRJ, 1993.

SCHWARCZ, L. O espetáculo das raças. Rio de Janeiro: Ed. UFRJ, 1995.

Recebido em: agosto/2005

Aceito em: novembro/2006 
